\title{
Activity limitation and disability due to pain in back and extremities in rural population: A community-based study during a period of twelve months in rural Gadchiroli, India
}

\author{
Anand A Bang ${ }^{1}$, \\ Shekhar Y Bhojraj², \\ Mahesh Deshmukh', \\ Sameer Kalkotwar², \\ Vinay R Joshi ${ }^{3}$, \\ Tushar Yarmal ${ }^{4}$, \\ Yogesh Kalkonde ${ }^{1}$, \\ Abhay T Bang ${ }^{1}$ \\ ${ }^{1}$ Society for Education, \\ Action and Research \\ in Community Health \\ (SEARCH), Gadchiroli, \\ Maharashtra, India \\ ${ }^{2}$ Spine Foundation, \\ Mumbai, Maharashtra, \\ India \\ ${ }^{3}$ Hinduja Hospital and \\ Research Center, Mumbai, \\ Maharashtra, India \\ ${ }^{4}$ Naraindas Morbai \\ Budhrani Trust, Mumbai, \\ Maharashtra, India
}

\begin{abstract}
Background Population based estimates of the extent of the activity limitation due to back pain and disability due to musculoskeletal pains are lacking from rural India. We estimated this burden as a) extent of activity limitation due to back pain, b) disability due to musculoskeletal pains, c) grading of the limitation of each activity due to back and musculoskeletal pain in the rural adult population in Gadchiroli, India.
\end{abstract}

Methods This population-based, cross-sectional study was conducted in two villages randomly selected from a cluster of 7 eligible villages in Gadchiroli district of India. All adults $\geq 20$ years in these villages were surveyed by the trained community health workers in January 2010. Disability due to back pain was evaluated using newly developed questionnaire for women and men which assessed limitations in the gender-specific daily household and occupational activities in a rural area. Disability due to pain in extremities was assessed using the Health Assessment Questionnaire (HAQ).

Results The total population of the two villages was 3735 out of which 2535 (67.9\%) were adults $\geq 20$ years of age and were eligible to participate in the study. Of these, 2259 (89\%) were interviewed and 1247 participants (55\%) had any pain on the day of the survey. Activity limitation questionnaire was filled for 716 (91.4\%) out of 783 patients with back pain. HAQ scale was filled for 524 (85.2\%) out of 615 patients with pain in extremities. Among men with back pain, respectively 11\%, 19\%, 60\% and 11\% had no, mild, moderate to severe difficulty or were completely unable to perform agrarian work, while among women, respectively $6 \%, 20 \%, 69 \%$ and $4 \%$ had no, mild, moderate to severe difficulty or were completely unable to perform household activities. Based on the HAQ score, respectively 1\%, $67 \%, 18 \%$ and $14 \%$ of the participants had no, mild, moderate to severe disability or were completely unable to perform the activities.

Conclusions This community-based study in rural Gadchiroli demonstrates significant mild to moderate disability and activity limitation, due to pain in back and extremities in a population involved in hard manual work, especially agricultural and underlines the need to address the problem through appropriate interventions. The study also employs for the first time an indigenously developed questionnaire to identify activity limitation due to back pain, and demonstrates the method as well as the questionnaire.

Back pain (BP) and musculoskeletal pain (MSP) are the commonest form of chronic pain, causing disability and health care expenditure world over [1-4]. Additionally, low back pain (LBP) is the one of the most important cause of activity limitation in both men and women [5] as well as the second most frequent reason, after upper respiratory infections, for physician visits [6,7]. As heavy manual labor is a known risk factor for back and musculoskeletal pain [8], agrarian rural communities are at a high risk of BP and MSP [9-11] as well as disability and activity limitation. 
The Health Assessment Questionnaire (HAQ) is a standardized tool for measuring disability due to musculoskeletal pains and has been used in Indian setting [12]. But disability and limitation to activities of daily living (ADL) due to low back pain are difficult to assess; and are measured by patient perceived responses in a questionnaire, either written or interview based. The two most commonly used LBP disability questionnaires, Roland-Morris (RM) and Oswestry, could not be used with the rural population in Gadchiroli as these Scales were developed in Europe, North America or Australia and consisted of inquiries regarding climbing stairs, driving and similar other activities inappropriate to rural Indian setting. Consequently, there was absence of culture specific questionnaire to measure disability due to low back pain in a rural population of India.

Hence population-based data from rural India on the burden of disability due to back pain and musculoskeletal pains is significantly lacking, limiting the possibility of developing appropriate interventions [12]. Therefore, in this study we aimed to develop an activity limitation questionnaire and estimate the activity limitation due to low back pain and disability due to musculoskeletal pains in the adult population in rural Gadchiroli in Central India.

\section{METHODS}

\section{Study setting, design and sample size}

This study of activity limitation due to pain in back and disability due to musculoskeletal pains was nested in a population-based, cross-sectional, interview based survey of the prevalence of PBE in rural Gadchiroli. The study setting, study design, detail method of sample size calculation, method of village selection including the eligibility criteria are described in detail [13].

\section{Designing local questionnaire for the assessment of activity limitation due to pain in back}

The disability scales available in the western literature for back pain such as the Oswestry Disability Scale (ODI), the Rolland Morris (RM) Scale, WHO Health Assessment Questionnaire were reviewed and found to be not applicable to the community from rural Gadchiroli, and most probably to population across Rural India. Some activities of daily living mentioned in the western scales were rare in rural community such as climbing steps inside the house. If these activities are removed from the available disability Scales, then the standardized scoring system of these Scales distorts and the score thus obtained does not hold true. Also, Scales like ODI were designed for a population which can self-administer the scale which was not possible considering the low literacy level of our population. Additionally, these Scales were considered too lengthy to be administered in the field. Lastly, in the rural community, the activities of males and females can differ significantly. Hence it was deemed inappropriate to use a single disability scale for both the genders. To test these observations we translated RM scale and ODI in Marathi, the vernacular local language. These questionnaires were distributed to the focus groups of male and female community health workers numbering 60 from the local rural community and discussed with in depth. Their feedback matched with our above observations.

Therefore, we decided to develop a new 'Rural Indian Activity Limitation Questionnaire' (RIALQ) to assess the activities of daily living that may be affected by back pain in rural Gadchiroli. We applied the following principles while developing this questionnaire; 1) there should be participation of the local community, taking into account their daily activities, understanding which of their activities are limited due to back pain, and what according to them are the important activities amongst the limited ones; 2 ) the list of activities should be comprehensive and representative of different postures associated with the use of back but not too long making it impossible to use in field and that 3) develop gender specific questionnaires reflecting their respective daily activities. Based on these, we decided to include maximum 11 questions in the questionnaire which in our experience would ensure feasibility of administration without compromising on the quality.

RIALQ was developed through several steps. First, Focus Group Discussion (FGDs) were conducted with the community health workers (CHWs), separately with males and females. The CHWs were asked to make a free list all the activities limited due to back pain. A total 30 activities for males and females were identified. Second, the CHWs were individually asked to rank the selected activities by scoring on a scale of 0-10, and were advised to score higher for the activities which were done more frequently and / or were considered more important. Finally, the CHWs were asked to score which activity they would want to be treated on the highest priority if they were unable to perform the same due to back pain, reflecting the intervention priorities. The mean of the score by the CHW for each of the activities were calculated. The activities were classified into different key postures and the activities which topped the list from each of the postural group were picked up giving the final list of eleven activities for women and men each. 
RIALQ was tested by administering to a conveniently selected sample of individuals in the rural clinic at Society for Education, Action and Research in Community Health (SEARCH) and in the villages by the field supervisors. Accordingly, the language of the various questions in the questionnaire was modified and the final questionnaire was developed. A simple scoring system of no difficulty (0), mild (1) and moderate difficulty (2) and cannot do the activity at all (3) was applied to RIALQ making 33 as the highest score for any individual signifying maximum activity limitations.

For musculoskeletal pains, the standard HAQ with standardized scoring system with 3 as the highest disability score for each of the 12 questions was used, making 36 as the highest score signifying maximum disability.

\section{Questionnaires}

The HAQ questionnaire asked the participants whether they had no difficulty, mild difficulty, moderate to severe difficulty in doing certain activities or could not do the said activity at all. The activities assessed were wearing clothes, sleeping and getting up from wooden bed, lifting a full glass or cup to mouth, walking on plain ground, bathing and wiping body dry, squatting to defecate or sitting on the floor folding legs, bending down to lift things, using the tap, boarding and getting down from bus or any other vehicle, walking a distance of $3 \mathrm{~km}$, shopping in vegetable market or grocery and climbing few steps.

The RIALQ used in men assessed the level of difficulty felt in performing various activities in the same way. The activities assessed were performing agrarian tasks such as ploughing or harvesting, cutting wood, lifting heavy things by bending or carrying and lifting on head, squatting for or getting up after defecation, travelling by bus, sitting upright or straight, standing for long time, sitting for long time, regular walking, walking farmlands or climbing up riverbeds (whether it is painful and needs support of stick or another person) and how was the sleep.

The RIALQ used in women assessed the level of difficulty felt in performing various activities as performing agrarian tasks such as sowing, harvesting, cutting of grass, household tasks as sweeping, cooking and washing clothes, drawing water from well or bore well, lifting heavy things by bending or carrying and lifting on head (items such as wooden logs, grass and water pots), squatting for or getting up after defecation, travelling by bus, sitting upright or straight, standing for long time, sitting for long time, regular walking, walking farmlands or climbing up riverbeds (whether it is painful and needs support of stick or another person) and how was the sleep.

\section{Training, quality control and data collection}

All the field supervisors were trained in interviewing the participant using RIALQ in case of pain in back and HAQ for pain in extremities. Data were collected from 1 January 2010 to 25 January 2010 during which information about the immediate past 12 months from January 2009 to January 2010 was recorded, details of which are described detail in the previous paper [13]. The patients with pain in the back and extremities (PBE) were identified during a cross-survey by the CHWs and were referred to a village clinic organized in the first week of February 2010, staffed by a team of spine surgeons and rheumatologists. Trained field supervisors' interviewed these individuals and filled the HAQ and RIALQ.

\section{Statistical methods}

A database was constructed for data entry using FOX PRO Version 2.0. The data were double entered, validated and checked for inconsistencies. Descriptive statistics included mean, medians and ranges for continuous variables and proportions for categorical variables were estimated. Analyses were conducted using Stata 10.0 (State Corp, College Station, Texas, USA).

\section{Ethical approval}

The research followed the tenets of the Declaration of Helsinki. Ethical approval for this nested study was granted as part of the main study, by the Institutional Ethical Committee of SEARCH formed according to the guidelines by the Indian Council for Medical Research. Consent was obtained first at the cluster level in the study villages 15 days before starting the survey. The community leaders (Village Council Leaders and members, school teacher and presidents of microfinance self-help groups) were explained the purpose and scope of the study including the benefits to the villagers (availability of referral care in SEARCH clinic and the care through a village clinic). Informed written consent in vernacular language in a standard format was obtained from individual participants after explaining the nature and benefits of the study. The benefits provided during the study included free consultation by spine surgeons and rheumatologists in a clinic conducted in the same 
Table 2. Disability due to musculoskeletal pains in rural Gadchiroli measured on the HAQ* scale $(n=524)$

\begin{tabular}{|c|c|c|c|c|}
\hline QUESTION & $\begin{array}{c}\text { NO DIFFICULTY } \\
(\%)\end{array}$ & $\begin{array}{l}\text { MILD DIFFICULTY } \\
(\%)\end{array}$ & $\begin{array}{l}\text { MODERATE TO } \\
\text { SEVERE } \\
\text { DIFFICULTY (\%) }\end{array}$ & $\begin{array}{l}\text { CANNOT DO } \\
\text { AT ALL (\%) }\end{array}$ \\
\hline & 0 & 1 & 2 & 3 \\
\hline Wearing clothes & 53 & 26 & 20 & 1 \\
\hline Sleeping and getting up from wooden bed & 23 & 44 & 33 & 0 \\
\hline Lifting a full glass or cup to mouth & 75 & 20 & 6 & 0 \\
\hline Walking on plain ground & 42 & 36 & 21 & 1 \\
\hline Bathing and wiping body to dry & 52 & 31 & 17 & 1 \\
\hline Squatting to defecate or sitting on the floor folding legs & 26 & 38 & 30 & 6 \\
\hline Bending down to lift things & 40 & 39 & 20 & 1 \\
\hline Using the tap & 80 & 14 & 5 & 1 \\
\hline Boarding and getting down from bus or any other vehicle & 34 & 41 & 23 & 2 \\
\hline Walking $3 \mathrm{~km}$ & 22 & 39 & 31 & 8 \\
\hline Shopping in vegetable market or grocery & 36 & 29 & 23 & 12 \\
\hline Climbing few steps & 24 & 34 & 32 & 10 \\
\hline
\end{tabular}

HAQ - Health Assessment Questionnaire

steps, walking three kilometres and squatting to defecate. Overall, no difficulty (zero), mild difficulty (>zero and $\leq 1$ ), moderate to severe difficulty $(>1$ and $\leq 1.5)$ and complete inability $(>1.5)$ to do an activity was identified in $1.3 \%, 67 \%, 17.6 \%$ and $14.1 \%$ of the participants respectively (Table 3 ).

Table 3. Categorization of $\mathrm{HAQ}^{*}$ score according to severity

\begin{tabular}{|c|c|c|c|c|c|c|}
\hline \multirow{2}{*}{ SCALE } & \multicolumn{2}{|c|}{ PARTICIPANTS } & \multicolumn{2}{|c|}{ MALE PARTICIPANTS } & \multicolumn{2}{|c|}{ FEMALE PARTICIPANTS } \\
\hline & $\mathrm{n}$ & $\%$ & $\mathrm{n}$ & $\%$ & n & $\%$ \\
\hline No difficulty (0) & 7 & 1.3 & 5 & 2.5 & 2 & 0.6 \\
\hline Mild difficulty $(>0 \& \leq 1)$ & 351 & 67.0 & 136 & 67.7 & 215 & 66.6 \\
\hline Moderate (>1 \& $\leq 1.5)$ & 92 & 17.6 & 38 & 18.9 & 54 & 16.7 \\
\hline Severe (>1.5) & 74 & 14.1 & 22 & 10.9 & 52 & 16.1 \\
\hline Total forms filled & 524 & 100.0 & 201 & 100.0 & 323 & 100.0 \\
\hline Mean (SD) & \multicolumn{2}{|c|}{$0.86(0.54)$} & \multicolumn{2}{|c|}{$0.80(0.52)$} & \multicolumn{2}{|c|}{$0.90(0.54)$} \\
\hline $\mathrm{CI}$ & \multicolumn{2}{|c|}{$(0.81,0.91)$} & \multicolumn{2}{|c|}{$(0.73,0.87)$} & \multicolumn{2}{|c|}{$(0.85,0.95)$} \\
\hline $\begin{array}{l}\text { Mean (SD) (from actual score) (11 question } \\
\text { with max. } 3 \text { score each }=33 \text { score) }\end{array}$ & \multicolumn{2}{|c|}{$10.36(6.43)$} & \multicolumn{2}{|c|}{$9.65(6.27)$} & \multicolumn{2}{|c|}{$10.80(6.54)$} \\
\hline CI & \multicolumn{2}{|c|}{$(9.8,10.91)$} & \multicolumn{2}{|c|}{$(8.77,10.52)$} & \multicolumn{2}{|c|}{$(10.1,11.5)$} \\
\hline
\end{tabular}

HAQ - Health Assessment Questionnaire, SD - standard deviation, CI - confidence interval

\section{Disability due to pain in extremities according to gender}

The gender specific disability score showed higher burden of disability in women compared to men (Table 3 , Tables S1 and S2 in the Online Supplementary Document, and Figure 2 and Figure 3). Overall, no difficulty (zero), mild difficulty ( $>$ zero and $\leq 1$ ), moderate to severe difficulty $(>1$ and $\leq 1.5)$ and complete inability $(>1.5)$ to do an activity was identified in $2 \%, 68 \%, 19 \%$ and $11 \%$ of the men participants respectively and $1 \%, 67 \%, 17 \%$ and $16 \%$ women participants respectively.

\section{Activity limitation due to back pain in men}

Of the 241 men participants, a significant $47 \%$ had no difficulty in getting sound sleep, whereas only $11 \%$ had no difficulty in agrarian work. Mild difficulty was faced by $46 \%$ and $42 \%$ in sitting and standing for long time respectively. Significant proportion of participants $(60 \%)$ faced moderate to severe difficulty in agrarian work, followed by lifting heavy things or bending (42\%). These two activities were also represented by the maximum participants in the category 'cannot do at all', with $11 \%$ each (Table 4).

\section{Activity limitation due to back pain in women}

Of the 471 women participants, a significant $47 \%$ had no difficulty in getting sound sleep. Mild difficulty was faced by $43 \%$ and $40 \%$ in sitting for long time and regular walking and standing for long time, respectively. 


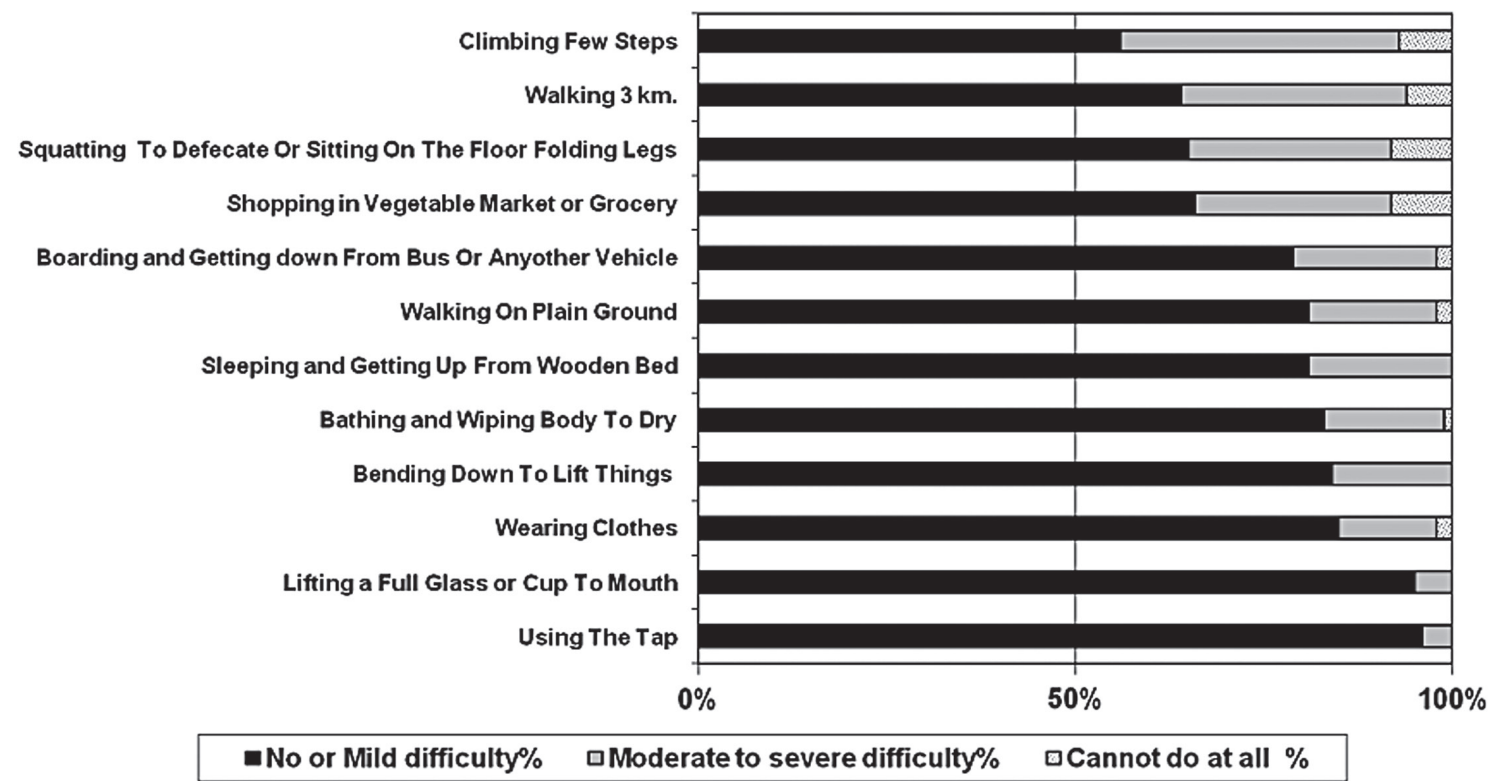

Figure 2. Disability in men due to musculoskeletal pains in rural Gadchiroli measured on the HAQ scale ( $\mathrm{n}=201)$. HAQ - Health Assessment Questionnaire.

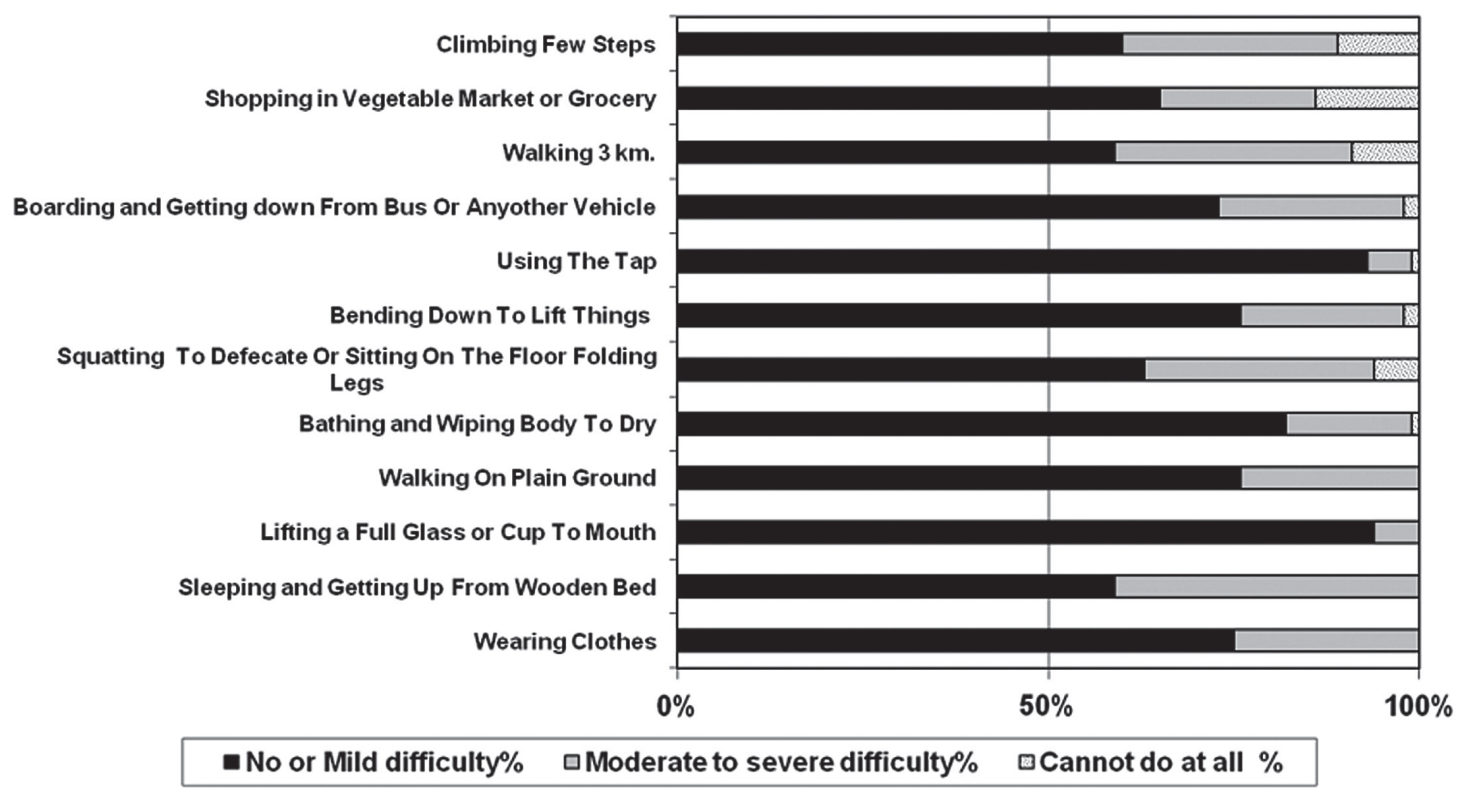

Figure 3. Disability in women due to musculoskeletal pains in rural Gadchiroli measured on the HAQ scale $(n=323)$. HAQ - Health Assessment Questionnaire.

A large proportion of participants faced moderate to severe difficulty in household (69\%) and agrarian tasks (64\%). $12 \%$ of the participants were completely unable to perform agrarian tasks while $10 \%$ were unable to lift heavy loads by bending or carrying on head (Table 5).

\section{DISCUSSION}

Overall, we found that though a significant proportion of community suffers from PBE, the nature of disability is mild in most of the individuals for most of the routine activities. For the first time, we also developed and used a culture specific questionnaire (RIALQ) for understanding the effect of BP on activities of daily living in the local rural community. 
Table 4. Activity limitation due to back pain in men in rural Gadchiroli $(n=245)$

\begin{tabular}{|c|c|c|c|c|}
\hline ACTIVITY & $\begin{array}{l}\text { No } \\
\text { DIFFICULTY \% }\end{array}$ & $\begin{array}{l}\text { MILD } \\
\text { DIFFICULTY } \%\end{array}$ & $\begin{array}{c}\text { MODERATE } \\
\text { TO SEVERE } \\
\text { DIFFICULTY \% }\end{array}$ & $\begin{array}{l}\text { CANNOT DO } \\
\text { AT ALL } \%\end{array}$ \\
\hline & 0 & 1 & 2 & 3 \\
\hline Agrarian tasks (ploughing, harvesting) & 11 & 19 & 60 & 11 \\
\hline Cutting wood & 16 & 33 & 43 & 8 \\
\hline Lifting heavy things by bending or lifting and carrying on head & 16 & 31 & 42 & 11 \\
\hline Squatting or getting up after defecation & 39 & 38 & 21 & 3 \\
\hline Travelling by bus & 43 & 39 & 18 & 0 \\
\hline Sitting upright/straight & 31 & 41 & 27 & 1 \\
\hline Standing for long time & 34 & 42 & 21 & 3 \\
\hline Sitting for long time & 24 & 46 & 30 & 1 \\
\hline Regular walking & 36 & 37 & 24 & 2 \\
\hline $\begin{array}{l}\text { Walking farmlands or climbing up riverbeds (pains and need } \\
\text { support of a stick or a person) }\end{array}$ & 20 & 33 & 40 & 7 \\
\hline Sound sleep & 47 & 32 & 20 & 1 \\
\hline
\end{tabular}

Table 5. Activity limitation due to back pain in women in rural Gadchiroli $(n=471)$

\begin{tabular}{|c|c|c|c|c|}
\hline ACTIVITY & $\begin{array}{l}\text { No } \\
\text { DIFFICULTY } \%\end{array}$ & $\begin{array}{l}\text { MILD } \\
\text { DIFFICULTY\% }\end{array}$ & $\begin{array}{l}\text { MODERATE } \\
\text { TO SEVERE } \\
\text { DIFFICULTY\% }\end{array}$ & $\begin{array}{l}\text { CANNOT DO } \\
\text { AT ALL } \%\end{array}$ \\
\hline & 0 & 1 & 2 & 3 \\
\hline Household tasks (sweeping, cooking, washing clothes) & 6 & 20 & 69 & 4 \\
\hline Drawing water from well/bore well & 21 & 34 & 39 & 6 \\
\hline Agrarian tasks (sowing, harvesting, cutting of paddy or grass) & 8 & 15 & 64 & 12 \\
\hline Sitting upright/straight & 20 & 33 & 46 & 1 \\
\hline $\begin{array}{l}\text { Lifting heavy things by bending or carrying on head (wood } \\
\text { logs/grass/water pots) }\end{array}$ & 11 & 37 & 42 & 10 \\
\hline Squatting and getting up after defecation & 38 & 30 & 31 & 1 \\
\hline Standing for long time & 24 & 38 & 36 & 3 \\
\hline Sitting for long time & 18 & 43 & 38 & 1 \\
\hline Regular walking & 24 & 40 & 33 & 3 \\
\hline $\begin{array}{l}\text { Walking farmlands or climbing up riverbeds, (pains and need } \\
\text { support of stick or person) }\end{array}$ & 11 & 38 & 42 & 9 \\
\hline Sound sleep & 47 & 35 & 17 & 1 \\
\hline
\end{tabular}

We observed that despite significant period prevalence of BP (76\%) and musculoskeletal pains (71\%) [13], relatively less participants were completely unable to do an activity. For example, only $11 \%$ of men and $12 \%$ of women with back pain were absolutely unable to do agrarian tasks. Similarly, the proportion of participants with pain in extremities, who were completely unable to perform an activity was less than $10 \%$ for most of the activities. This finding is similar to another study in rural Indian setting [12]. Interestingly these findings with respect to disability also corroborate with the intensity of pain, which was mostly mild (81\%) suggesting that majority of the participants with PBE are suffering with mild pain and disability. This underlines need to identify or develop appropriate community based interventions which may allow earlier return to work through coping up and identifying alternative activities, so as to allow uninterrupted daily living.. However more significant activity limitation in agrarian tasks is worrisome as in an agrarian community livelihood is dependent on manual labor and indicates need to develop intervention to reduce higher frequency of moderate to severe disability among those with pain in back. Possible interventions to reduce this disability could be use of pain relieving agents and community-based rehabilitation for postural corrections, muscle strengthening. Given the high prevalence of PBE, the interventions to reduce disability due to PBE needs to be available at community level.

To the best of our knowledge, this is the first study from rural India reporting disability due to PBE a community that is largely agrarian and involved in manual labour. Other studies were from communities with less preponderance of manual agrarian labour [12].

The study had several strengths. The two study villages were randomly selected from a list of villages after excluding atypical (too large, too small, peri-urban villages with a primary health centre) villages. The participation rate of the adults in the villages was high. The data collection was done by CHWs with more than 15 
years of experience and was done using a systematically developed rural activity-specific questionnaire and HAQ. The possibility of incomplete or inaccurate data collection was minimized by rigorous training of CHWs in using the questionnaires, rigorous supervision and quality checks during data entry.

A key limitation of the study was the possibility of recall loss by the participants which would probably underestimate rather than overestimate the disability. The villages where the study was conducted had male and female CHWs who routinely provided subsidized treatment for pains with tablet aspirin for the past 20 years. This can also reduce duration and intensity of pain and the disability. On the other hand, we also cannot rule out that some of the participants may have overstated the disability.

\section{CONCLUSION}

In conclusion, this population-based study in rural Gadchiroli demonstrates predominantly mild to moderate disability due to PBE, except for agrarian tasks for men and women and household tasks for women where more than $60 \%$ individuals with PBE reported moderate to severe disability. The higher frequency of disability in performing agrarian tasks calls for interventions to reduce this disability as the livelihood of the population is dependent on agrarian tasks. The study also employs for the first time an indigenously developed questionnaire to identify activity limitation due to back pain in rural, agrarian areas.

\footnotetext{
Acknowledgements: We thank the people, community health workers, volunteers and leaders of the village Mudza and
Bamhani who participated in the study and made all the arrangements. We thank Dr Rani Bang, Co - Director, SEARCH,
Gadchiroli for her support in conceiving and conducting the study.
Funding: The study was funded by Sir Dorabji Tata Trust, the Spine Foundation, Mumbai, and SEARCH, Gadchiroli, India.
Authorship contributions: Conceived and designed the study: AAB, ATB, SYB, VRJ, MD, SK. Conducted the study: AAB,
MD, TY, ATB. Analysed the data: MD, AAB, YK, ATB. Contributed materials/analysis tools: ATB, SYB, SK, VRJ. Wrote the
draft manuscript: AAB. Reviewed the manuscript: YK, ATB.
Competing interests: The authors completed the ICMJE Declaration of Interest Form (available upon request from the
corresponding author) and declare no conflict of interest.
Additional material
Online Supplementary Document
}

1 Woolf AD. The Bone and Joint Decade 2000-2010. Ann Rheum Dis. 2000;59:81-2. Medline:10666159 doi:10.1136/ard.59.2.81

2 Ehrlich GE. Low back pain. Bull World Health Organ. 2003;81:671-6. Medline:14710509

3 Murray CJL, Vos T, Lozano R, Naghavi M, Flaxman AD, Michaud C, et al. Disability-adjusted life years (DALYs) for 291 diseases and injuries in 21 regions, 1990-2010: a systematic analysis for the Global Burden of Disease Study 2010. Lancet. 2012;380:2197-223. Medline:23245608 doi:10.1016/S0140-6736(12)61689-4

4 Campbell C, Muncer SJ. The causes of low back pain: a network analysis. Soc Sci Med. 2005;60:409-19. Medline:15522495 doi:10.1016/j.socscimed.2004.05.013

5 Golden AL, Kelsey JL, Mundt DJ. Epidemiology of low back pain. In: M.I.V.Jayson, editor. The Lumbar Spine and Back Pain. 4th ed. London: Churchill Livingstone; 1992.

6 Hart LG, Deyo RA, Cherkin DC. Physician office visits for low back pain. Frequency, clinical evaluation, and treatment patterns from a U.S. national survey. Spine. 1995;20:11-9. Medline:7709270 doi:10.1097/00007632-199501000-00003

7 Jacob T, Baras M, Zeev AEL. Physical Activities and Low Back Pain: A Community-Based Study. Med Sci Sports Exerc. 2004;36:9-15. Medline:14707761 doi:10.1249/01.MSS.0000106166.94343.02

8 Barrero LH, Hsu Y-H, Terwedow H, Perry MJ, Dennerlein JT, Brain JD, et al. Prevalence and Physical Determinants of Low Back Pain in a Rural Chinese Population. Spine. 2006;31:2728-34. Medline:17077743 doi:10.1097/01.brs.0000244583.35982.ea

9 Louw QA, Morris LD, Grimmer-Somers K. The prevalence of low back pain in Africa: a systematic review. BMC Musculoskelet Disord. 2007;8:105. Medline:17976240 doi:10.1186/1471-2474-8-105

10 Chopra A, Abdel-Nasser A. Epidemiology of rheumatic musculoskeletal disorders in the developing world. Best Pract Res Clin Rheumatol. 2008;22:583-604. Medline:18783739 doi:10.1016/j.berh.2008.07.001

11 Haq SA, Darmawan J, Islam MN, Uddin MZ, Das BB, Rahman F, et al. Prevalence of rheumatic diseases and associated outcomes in rural and urban communities in Bangladesh: a COPCORD study. J Rheumatol. 2005;32:348-53. Medline:15693098

12 Chopra A, Saluja M, Patil J, Tandale HS. Pain and disability, perceptions and beliefs of a rural Indian population: A WHO-ILAR COPCORD study. WHO-International League of Associations for Rheumatology. Community Oriented Program for Control of Rheumatic Diseases. J Rheumatol. 2002;29:614-21. Medline:11908580

13 Bang AA, Bang AT, Bhojraj SY, Deshmukh M, Yarmal T, Kalkotwar S, et al. Burden of pain in back and extremities in rural community: 12-month prevalence, distribution and duration of pain in Gadchiroli, India. J Glob Health. 2021;11:12001. doi:10.7189/jogh.11.12003 